\title{
ARTIGOS
}

\section{PROPOSTA DE USO DO CIMENTO \\ FOTOCATALÍTICO EM MOBILIÁRIO URBANO \\ - ESTUDO DE CASO EM PORTUGAL}

PROPOSAL FOR THE USE OF PHOTOCATALYTIC CEMENT IN URBAN FURNITURE - A CASE STUDY IN PORTUGAL

\section{BERNARDO METZNER SERRA REYNAULD DA SILVA | ILP \\ JOSÉ MANUEL COUCEIRO BAROSA CORREA FRADE, DR. | ILP \\ PAULO CESAR MACHADO FERROLI, DR. | UFSC}

\begin{abstract}
RESUMO
O cimento fotocatalítico tem a propriedade de limpar a poluição do ar, através da introdução de dióxido de titânio na pasta original. O uso deste material no mobiliário urbano pode proporcionar uma redução significativa no índice de poluição. Este artigo apresenta algumas propostas projetuais de mobiliário urbano com esse material em Portugal. A pesquisa foi realizada durante o período de agosto de 2019 a janeiro de 2020, na região de Leiria.
\end{abstract}

PALAVRAS CHAVE: Materiais; Mobiliário Urbano; Sustentabilidade

\begin{abstract}
Photocatalytic cement has the property of cleaning the air pollution by introducing titanium dioxide into the original paste. The use of this material in urban furniture can provide a significant reduction in the pollution index. This article presents some project proposals of urban furniture with this material in Portugal. The research was conducted during the period of August 2019 to January 2020, in the region of Leiria.
\end{abstract}

KEY WORDS: Materials; Urban furniture; Sustainability 


\section{INTRODUÇÃO}

Considera-se mobiliário urbano um conjunto de instalações no espaço público que tem por propósito atender as necessidades urbanas da comunidade. De acordo com a legislação mais recente, o termo mobiliário urbano significa "todo o elemento ou conjunto de elementos que, mediante instalação total ou parcial na via pública, por si ou instrumentalmente, se destine a satisfazer uma necessidade social ou a prestar um serviço, a título sazonal ou precário" (GIL, 2011).

Desta maneira, de acordo com esse Decreto-Lei, são exemplos de mobiliário urbano: paragens de autocarro, parques infantis, luminárias, ginásio ao ar livro, WC para animais, entre outros.

Ainda de acordo com Gil (2011) mobiliário urbano é definido como um conjunto de equipamentos de rua que estão inseridos em um espaço público com o propósito de oferecer serviços específicos e diferentes funções com resposta às necessidades da população. É de suma importância sua relação com arquitetura, design e engenharia, uma vez que esse tipo de interferência altera a paisagem urbana, sendo portanto necessário que tanto na forma, quanto nos materiais utilizados tenha-se o devido cuidado com fatores mercadológicos e culturais da região.

Com o passar do tempo o conceito foi mudando, consequência das novas tecnologias, mentalidade e crescimento das cidades. Isso levou a procura de novas formas e métodos de desenvolver este tipo de mobiliário e acrescentou itens que antes não eram usuais em espaços públicos. A consciência sustentável e ambiental tem vindo a ter grande influência e procura nos mercados nacionais e internacionais, onde o mercado do mobiliário de espaços públicos não é exceção. Neste contexto, a sustentabilidade é definida como a capacidade que o ser humano tem de interagir com o mundo, preservando a natureza e as gerações futuras e respeitando os três pilares básicos, o fator económico, o fator social e o fator ambiental. (LIBRELOTTO, 2009)

De acordo com as medidas ambientais europeias a legislação deve ser "respeitada por empresas e cidadãos para evitar custos mais altos com saúde, perda de receita pública e concorrência desleal entre empresas. Em todo o território europeu, diferentes autoridades públicas são responsáveis por promover, monitorar e fazer cumprir a legislação ambiental da UE. No entanto, eles enfrentam obstáculos como sistemas nacionais ineficientes, treinamento técnico insuficiente, baixo envolvimento da população e procedimentos inadequados de avaliação.
Com seu plano de ação de nove pontos para garantir a conformidade com os regulamentos ambientais, a Comissão Europeia pretende ajudar as autoridades públicas a promover, monitorar e fazer cumprir a legislação ambiental. A Comissão Europeia apresentou em meados de Dezembro do ano passado uma estratégia de políticas em prol do meio ambiente - o chamado Acordo Verde Europeu - contendo uma séria de propostas para lidar com temas diversos que incluíram a perda de biodiversidade, agricultura sustentável, novas regras ambientais, além de possíveis penalidades para os poluidores.

Com o Acordo Verde a Europa se comprometeu a tornar-se o primeiro continente do mundo a atingir a neutralidade climática, que na prática significa zerar o nível de emissões líquidas de carbono até 2050. (Deutsche Welle, 2019). Outras metas previstas no Acordo Verde incluem a redução do uso de pesticidas e fertilizantes na agricultura, e a introdução de um "ajuste de carbono nas fronteiras", com a intenção de incentivar emissores de gases do efeito estufa estrangeiros a tornarem-se mais ecologicamente corretos.

Visto que o desenvolvimento sustentável é um fio condutor para este projeto, é importante salientar a preservação das matérias-primas necessárias para produzir os materiais necessários para a fabricação deste tipo de produto. Posto isso, surge a urgência de otimizar o uso destes materiais.

Sendo que estes produtos são para uso público, a sua produção terá de ser suportada ecologicamente para uma produção em grande quantidade. Neste artigo são também apresentados conjuntos de propostas que demonstram inovação e sustentabilidade no uso do betão e cimento como material de construção de mobiliário urbano. Concluindo assim com a forma mais eficiente de introduzir e utilizar o cimento e ou betão fotocatalítico na produção de mobiliários urbanos.

O presente artigo inova no sentido de considerar o enfoque de mobiliário urbano sob a óptica de diversos profissionais que, direta ou indiretamente, participam do projeto de mobiliários urbanos, sejam estes artigos solitários na paisagem urbana ou integrantes de conjuntos pré-existentes ou complementares.

\section{REVISÃO}

Apesar do presente estudo de caso ter sido realizado em Portugal, com vistas a propostas futuras considerou-se também referências brasileiras, como a NBR 9050.

A norma NBR 9283 substituída pela NBR 9050 define mobiliário urbano como "Todos os objetos, elementos e pequenas construções integrantes da paisagem urbana, de natureza utilitária ou não, implantados mediante 
autorização do poder público em espaços públicos e privados" (ABNT, 2004, p.3). Considerando-se pois a referida norma pode-se considerar como mobiliário urbano: abrigos de ônibus, acessos ao metrô, esculturas, painéis, playgrounds, cabines telefônicas, postes, lixeiras, quiosques, relógios, bancos, e assim por diante.

A sustentabilidade é compreendida como uma ciência complexa, que resgata a importância do conhecimento generalizado, de forma integrada; ou seja, não se pode separar por eixos imaginários de conhecimento, onde necessariamente cada vertente (econômica, social ou ambiental) tem seu limite.

Neste contexto, a abordagem de um problema dificilmente pode ser resolvida por um único profissional de forma generalista, mas sim, obriga a integração de vários profissionais, ainda que especialistas em áreas específicas, cuja reunião de suas diferentes visões na resolução do referido problema, poderá trazer uma solução satisfatória.

A atividade projetual (que neste artigo aborda design de produto, arquitetura e engenharia) foi se alterando ao longo dos anos, acompanhando a própria evolução do conceito de eco-design e projeto sustentável.

Sendo a questão da sustentabilidade, principalmente em seus aspectos econômicos e ambientais, incorporada nas atividades pré-projetuais, sob a perspectiva inicial do eco-design, que foi definido por Manzini e Vezzoli (2002) como a atividade que liga o tecnicamente possível com o ecologicamente necessário, favoreceu o surgimento de novas propostas social e culturalmente aceitáveis. Com isso, as etapas iniciais do projeto do produto referem-se ao desenvolvimento de um novo conceito, a organização do projeto piloto e a seleção de materiais.

A finalização da evolução até o momento atual é o eco-design sendo acrescido, diante da realidade encontrada, para a plenitude do conceito (pelo menos da tríade moderna da sustentabilidade), com os eixos econômico, social e ambiental sendo considerados de forma integrada (modelo ESA - LIBRELOTTO, 2009).

Se tradicionalmente projetos desenvolvidos por engenheiros possuem mais evidência nos aspectos quantitativos, os projetos desenvolvidos por arquitetos e designers priorizam aspectos estético-sensoriais. Neste aspecto a sustentabilidade contribuiu para uma abordagem interdisciplinar, onde todos estes aspectos devem estar equilibrados na linguagem projetual de designers, arquitetos e engenheiros.

Montenegro (2005) explica que, diferente do mobiliário doméstico, o urbano não é adquirido pelo próprio usuário, que apenas faz uso dele. O usuário não é um cliente principal, pois não "escolhe" o objeto, tarefa realizada pelo poder público. Portanto, é possível que os gostos pessoais e específicos do indivíduo sejam protelados em prol de um senso comum. Cabe então ao profissional projetista de mobiliários urbanos um duplo desafio: o produto em questão deve estar ao mesmo tempo em conformidade com a herança cultural e histórica da comunidade regional, atento aos seus costumes, mas também deve buscar atrair visitantes, auxiliando na renda proporcionada pelo turismo.

Outra característica relevante é que existem vários tipos de mobiliários urbanos. Tem-se aqueles que de fato as pessoas utilizam (bancos e lixeiras, por exemplo), aqueles não utilizáveis, mas com viés informativo permanente ou para utilização indireta, como postes e placas (dentre outros), também existem os não utilizáveis com viés informativo ocasional e também aqueles com finalidades puramente artísticas, com esculturas e obras de arte em geral. A figura 1 mostra exemplos destes quatro tipo de mobiliários urbanos. A primeira imagem é da cidade de Poznan (Polônia), mostrando alguns mobiliários urbanos utilizáveis, a segunda imagem da figura 1 mostra uma placa informativa, também da cidade de Poznan; a terceira imagem mostra um exemplo encontrado em Lisboa (Portugal) sobre mobiliário urbano com caráter informativo ocasional e a última imagem mostra um exemplo artístico.
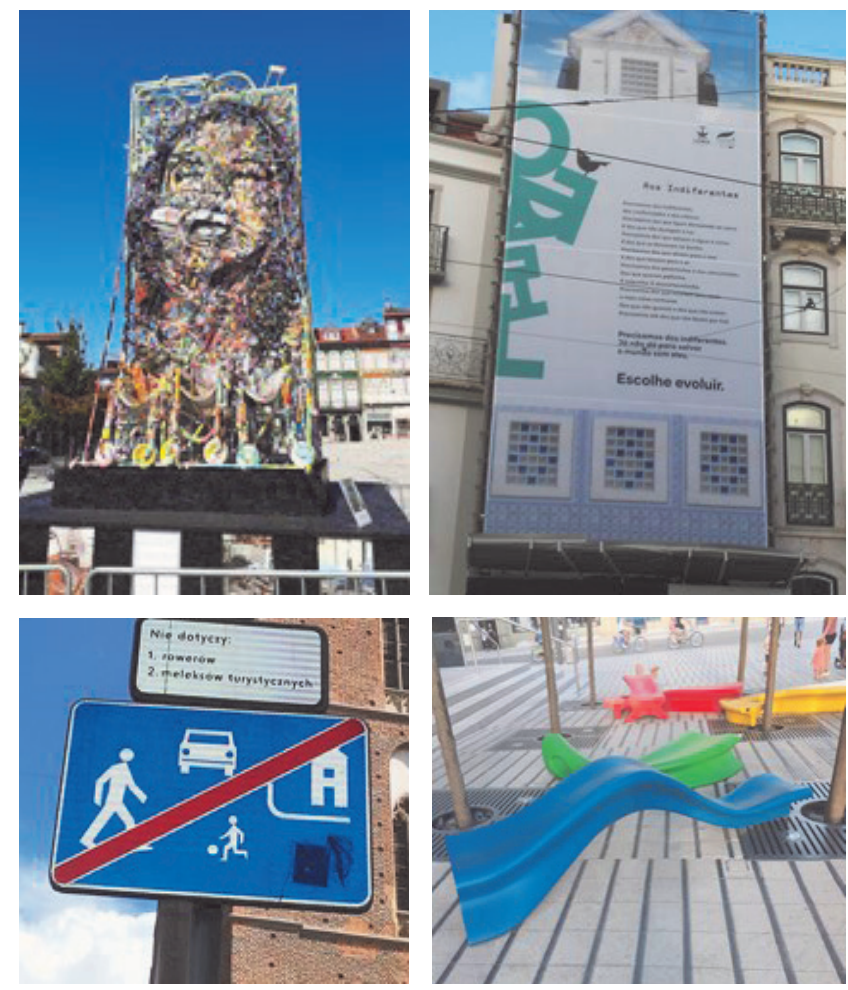

Figura 1 - Tipos de mobiliários urbanos. Fonte: própria. 
O que se entende por "espírito" de uma cidade pode ser relacionado e compreendido através de seu mobiliário urbano. Isso é o que afirma Heskett (2005). Acompanhando essa linha de raciocínio, pode-se encontrar relatos em entrevistas para jornais, revistas e sites, de designers e arquitetos (principalmente) explicando que esse "espírito" é alimentado hoje pela inclusão dos fatores ecológicos/ ambientais no mobiliário urbano. Objetiva-se com isso, transmitir a mensagem: nossa cidade (nosso país, nosso povo) se preocupa com o meio ambiente, com as questões econômicas, sociais e culturais vinculadas a isso.

Observa-se que esse tipo de mensagem é muito poderosa, influenciando diretamente no comportamento das pessoas. $\mathrm{O}$ vandalismo comporta-se como uma correlação negativa com relação a limpeza geral do ambiente (chão limpo, lixeiras higienizadas, paredes sem riscos ou pixadas, etc.). O contrário também é visível: um ambiente sujo e mal cuidado favorece atitudes desleixadas com relação aos mobiliários urbanos disponibilizados. Considera-se portanto, desse modo, que um mobiliário urbano projetado de forma harmoniosa com o entorno é uma condição básica para a valorização da cidade e de sua população.

Yucel (2013) considera que um projeto em que o mobiliário for planejado e coordenado em conformidade com o conceito de design mais abrangente é melhor do que aqueles que foram selecionados de uma forma fragmentada sem ter em conta as necessidades dos utilizadores, o caráter arquitetônico ou as condições do local.

\subsection{Procedimentos metodológicos}

Durante a pesquisa realizada nas cidades de Caldas da Rainha, Fátima e Leiria (Portugal), procurou-se definir qual é o tipo de mobiliário urbano mais utilizado pelo público, onde constatou-se que os mais usados são os bancos de jardim, em madeira e ferro, geralmente, e os ginásios ao ar livre, normalmente em aço e compósitos poliméricos. Ampliando-se a pesquisa, com imagens coletadas em viagens e também de estudos preliminares encontrados em Ferroli e outros (2019). Mostra-se na sequencia alguns mobiliários urbanos encontrados em cidades europeias com a presença de cimento ou betão, em geral acompanhados de outros materiais.

Na figura 2, tem-se, na primeira imagem, um mobiliário urbano encontrado na cidade de Innsbruck (Áustria), com o concreto de base para uma estrutura em madeira; na segunda imagem tem-se um mobiliário urbano encontrado na cidade de Bruxelas (Bélgica), também com o concreto usado de base para uma estrutura de madeira.
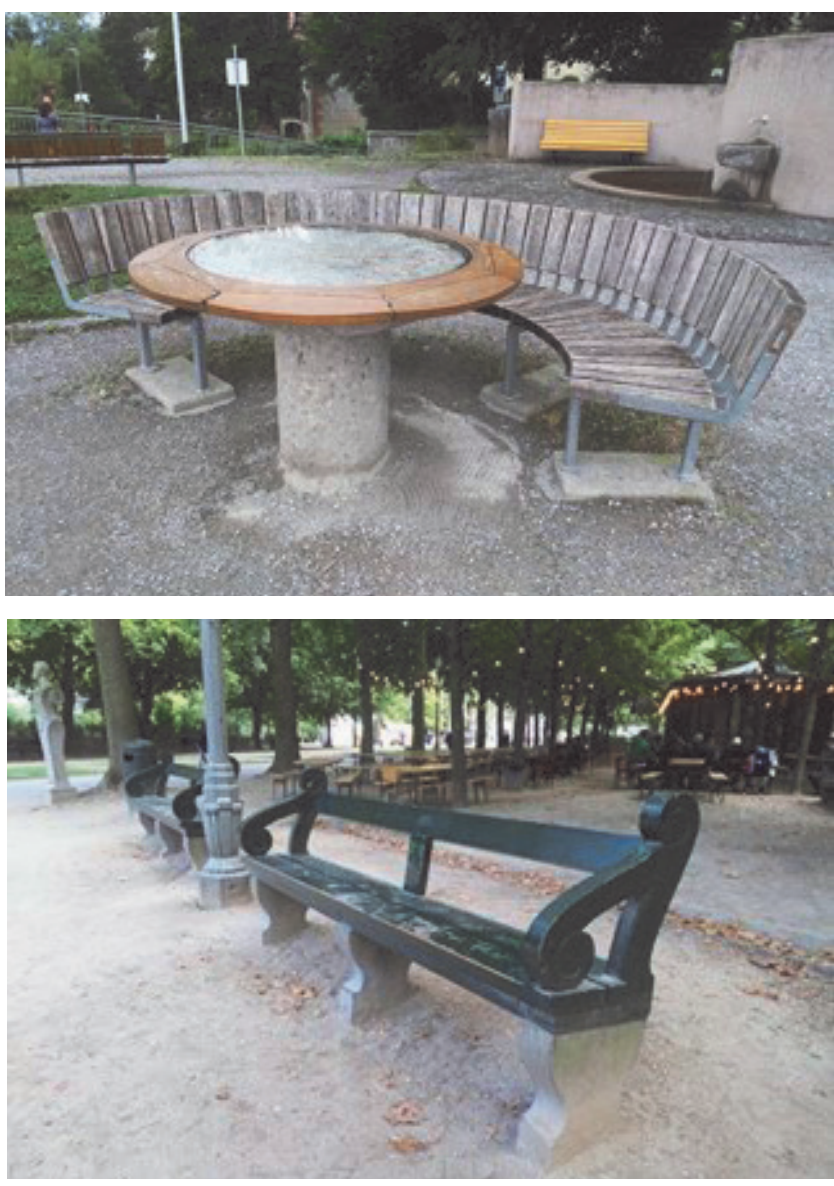

Figura 2 - Mobiliários urbanos em Inssbruck (Áustria) e em Bruxelas (Bélgica). Fonte: própria.

A figura 3 mostra, na primeira imagem, um mobiliário urbano encontrado em Sevilla (Espanha) com uma proposta interessante de união entre concreto e madeira. A segunda imagem da mesma figura mostra um mobiliário urbano encontrado em Nazaré (Portugal), com o cimento atuando como base, novamente com uso em comum com a madeira.

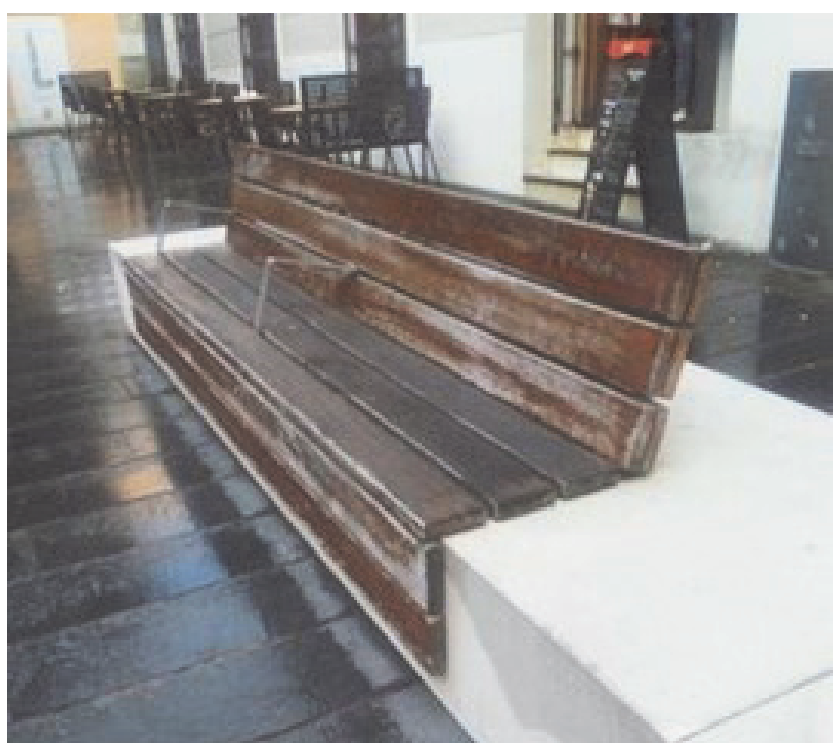




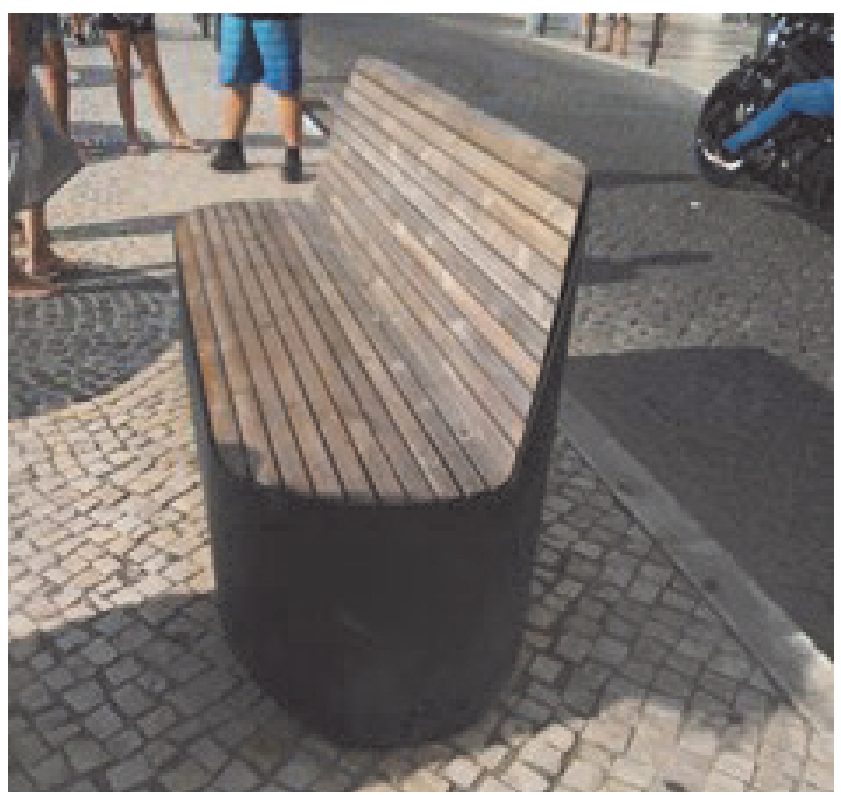

Figura 3 - Mobiliário urbano em Sevilla (Espanha) e Nazaré (Portugal). Fonte: própria.

Para o desenvolvimento deste artigo realizou-se uma pesquisa sobre vários materiais, sendo o cimento como base de toda a estrutura mobiliária e resíduos industriais que poderiam ser adicionados ao cimento e que formariam então um novo material sustentável.

O referido cimento é um aglomerante hidráulico que, em contato com a água, produz reação exotérmica de cristalização de produtos hidratados, ganhando assim resistência mecânica. É considerado o principal material de construção obtido a partir do cozimento de calcários naturais ou artificiais. Misturado com água forma um composto que endurece em contato com o ar. É também usado com a cal e a areia na composição das argamassas. $O$ cimento mais utilizado e conhecido, sobretudo na construção civil, é o cimento Portland. (CALLISTER JR e outros, 2016).

O primeiro passo no desenvolvimento do cimento foi em 1756 através de John Sematton, que conseguiu um produto de alta resistência por meio de calcinação e de calcários moles. Já em 1818, o francês Louis Vicat obteve resultados semelhantes adicionando uma mistura de compostos argilosos e calcários, tendo recebido o título de inventor do cimento artificial. Em 1824 o construtor civil Joseph Aspdin queimou uma mistura de pedras calcárias e argilas, que após seca, tornou-se tão dura como as pedras que eram utilizadas até então na construção. Esta mistura foi patenteada por Aspdin com o nome de cimento Portland, nome escolhido devido a sua coloração e dureza, semelhantes as rochas da ilha de Portland.

Com a evolução dos tempos, o material e as técnicas de construção foram se alterando. Houve o desenvolvimento do tijolo, das telhas e do asfalto (dentre outros), sendo que atualmente estes materiais são utilizados numa larga escala para produção de edifícios, casas, pontes, etc.

A figura 4 mostra exemplos de mobiliários urbanos modernos, mostrando que o material continua em evidência. O mobiliário, encontrado na cidade de Cracóvia (Polônia), mostra a composição do cimento com os polímeros industriais. A segunda imagem da figura detalha o mobiliário urbano mostrando que o mesmo possui placa solar, que permite aos usuários o carregamento de telemóveis, tablets e afins. Colocado neste nível, o cimento mostra-se como um material perfeitamente adequado as novas exigências sócio-ambientais.

Outro exemplo interessante é mostrado na figura 5, onde o cimento foi usado para composição de um mobiliário urbano para lazer. No primeiro, encontrado na cidade de Frankfurt (Alemanha), o mobiliário mostrado faz parte de um amplo conjunto de mobiliários urbanos construído para lazer e entretenimento, muitos deles em cimento e concreto. No exemplo o cimento foi usado para construção de uma mesa de ping pong. Na segunda imagem, encontrado em Badajoz (Espanha) um tradicional banco de praça.
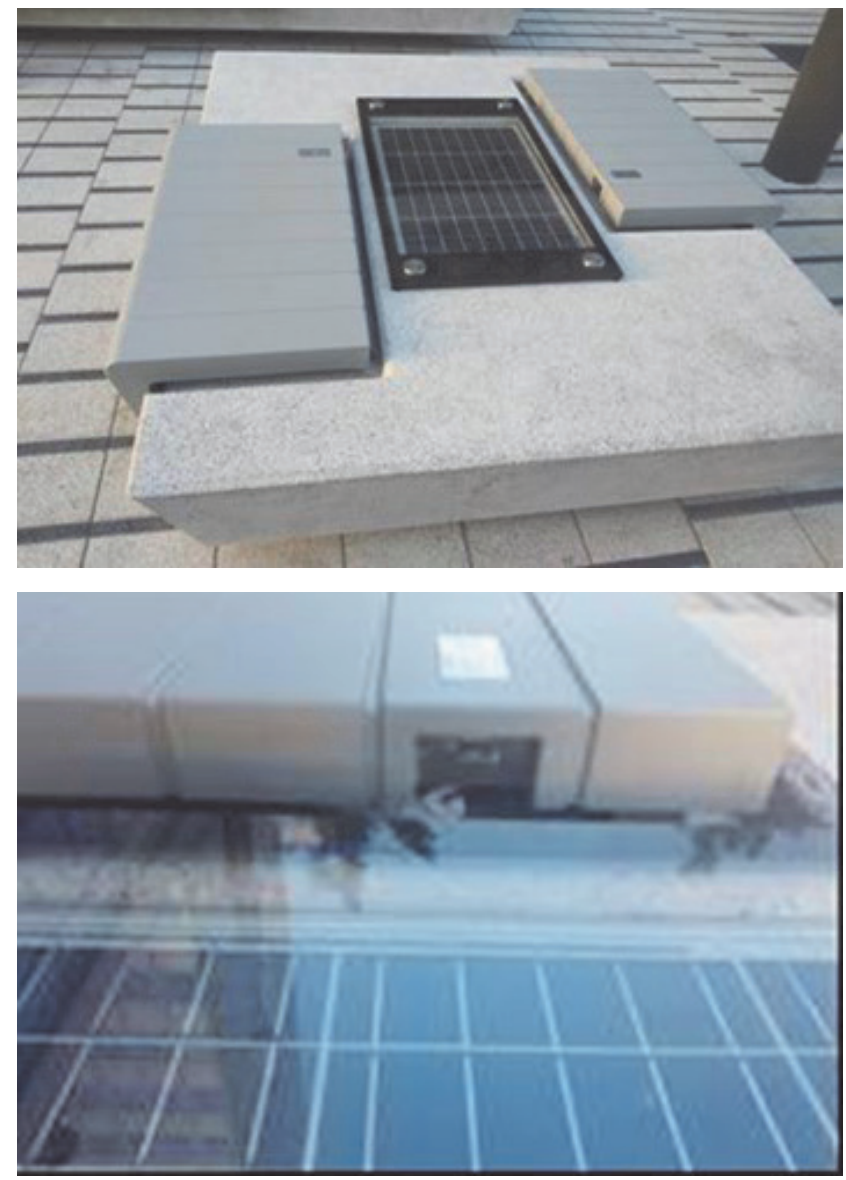

Figura 4 - Mobiliário urbano em Cracóvia (Polônia). Fonte: própria. 

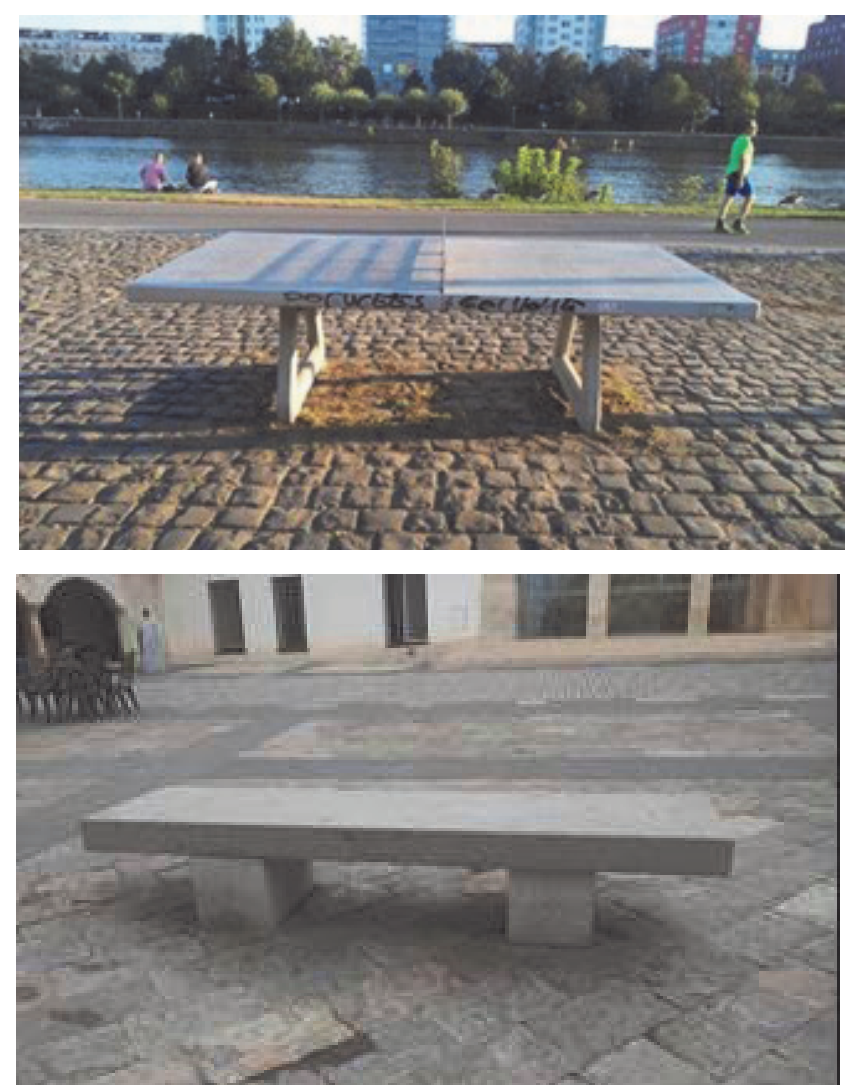

Figura 5 - Mobiliários urbanos em Frankfurt (Alemanha) e Badajoz (Espanha). Fonte: própria.

A figura 6 mostra mais dois exemplos do uso do cimento em mobiliários urbanos. A primeira imagem é de um mobiliário encontrado na cidade de Mérida, Espanha. A segunda é um exemplo de composição entre madeira e cimento, encontrado na cidade de Aveiro, Portugal. A figura 7 complementa as exemplificações mostrando, na primeira imagem um mobiliário urbano encontrado em Paris (França) com o cimento usado sem materiais compostos e na segunda imagem, de Lisboa (Portugal) um exemplo do cimento em composição com aço.

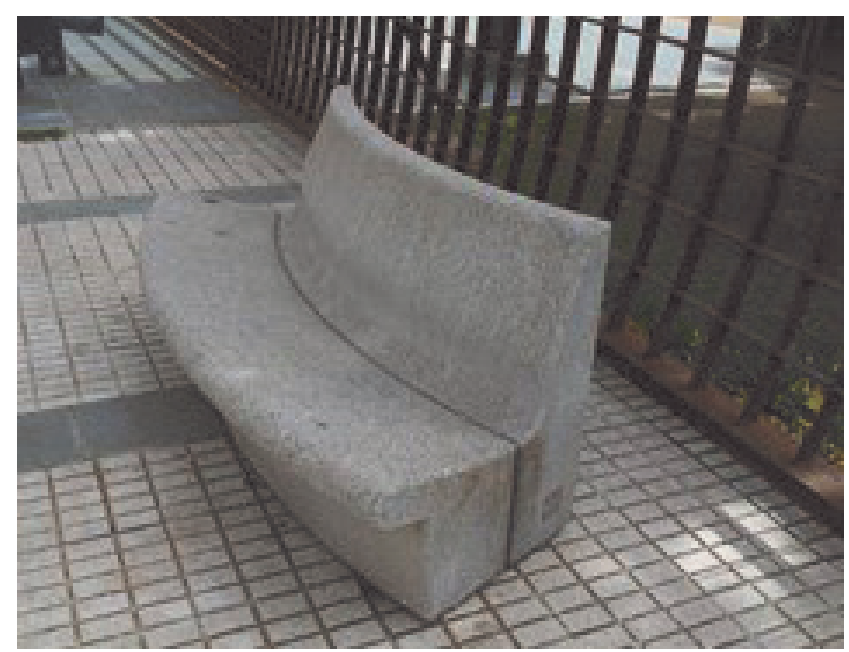

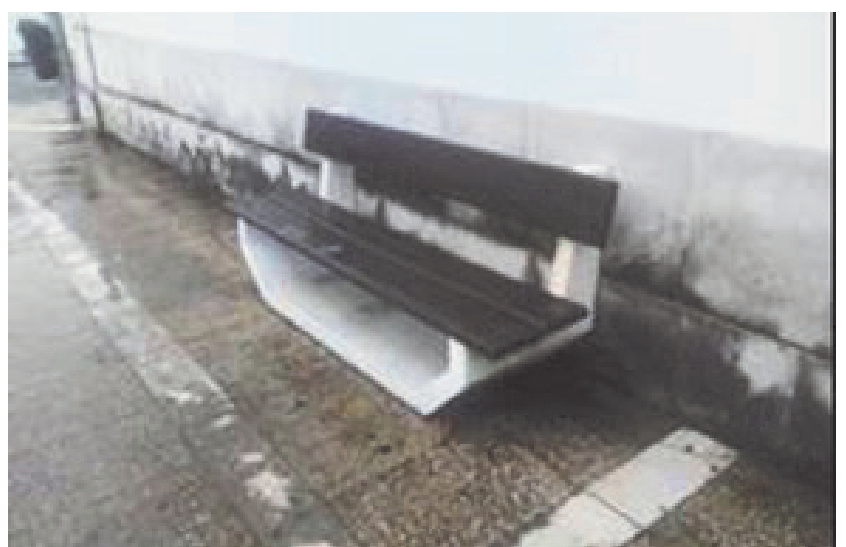

Figura 6 - Mobiliários urbanos em Mérida (Espanha) e Aveiro (Portugal). Fonte: própria.

Em relação composição, o cimento é um pó fino que resulta na mistura de várias substâncias, nomeadamente gesso e escória silicosa. Geralmente o cimento Portland simples é composto por aproximadamente $96 \%$ de clíquer e $4 \%$ de gesso. Já em relação aos resíduos industriais, foram selecionados para experimentação: resíduos de madeira, papel e fibra.
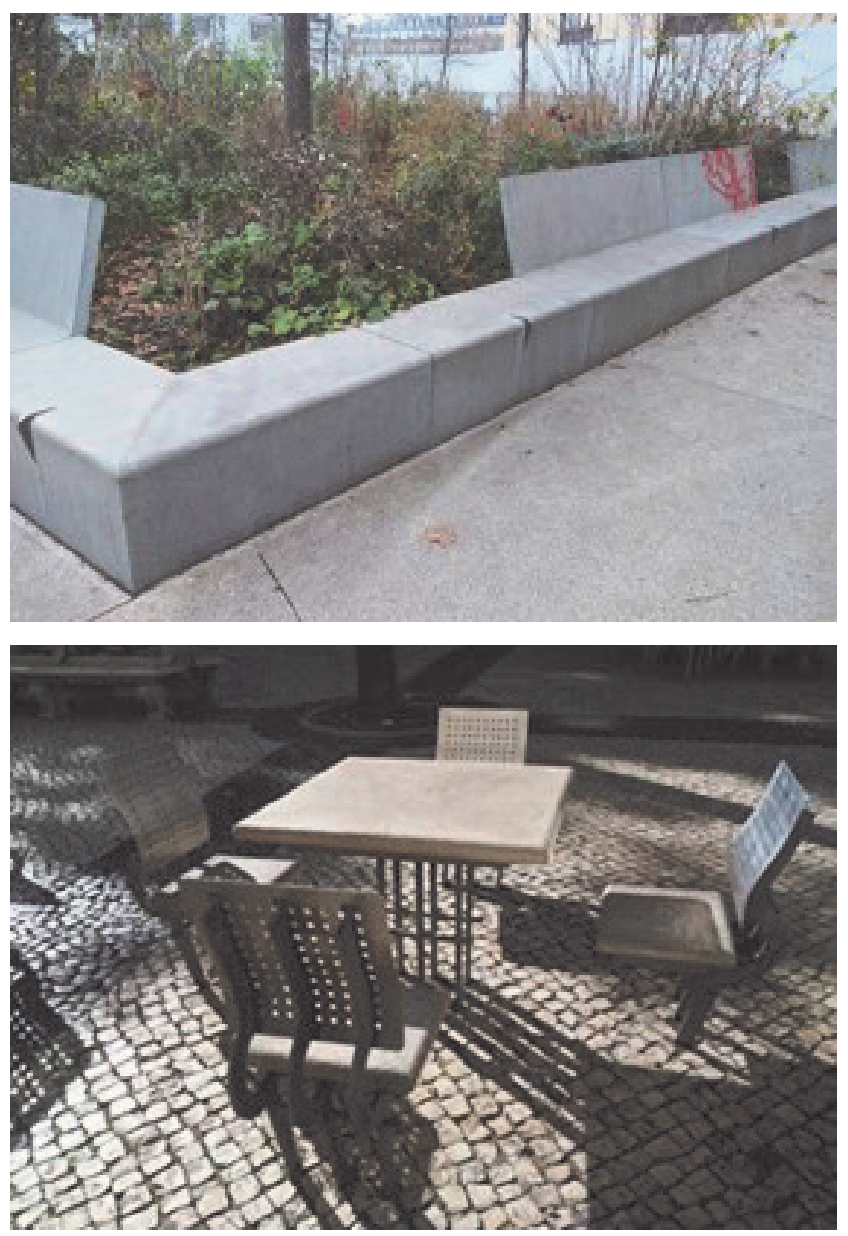

Figura 7 - Mobiliários urbanos em Paris (França) e Lisboa (Portugal). Fonte: própria. 


\section{PROJETOS COM USO DE CIMENTO FOTOCATALÍTICO}

O cimento fotocatalítico tem a propriedade de limpar a poluição do ar. Isto é conseguido introduzindo dióxido de titânio na pasta. Este agente reage a radiação solar, transformando agentes poluentes como óxidos de azoto em nitratos. Este material é maioritariamente usado como estrutural porém este projeto estuda a potencial utilização deste na construção de mobiliário urbano.

De acordo com Melo (2012), o uso de dióxido de Titânio (TiO2) tem sido bastante utilizado como elemento fotocatalítico para redução da poluição no Japão, especialmente para pavimentação de calçadas e margens de estradas.

O Dióxido de Titânio age principalmente na degradação de Óxidos de Nitrogênio (NOx) presentes na atmosfera, sem influenciar nas propriedades mecânicas da argamassa. No estudo de Melo (2012) constatou-se uma eficiência na degradação de NOx entre $45 \%$ a $95 \%$, dependendo do tipo e da porcentagem de $\mathrm{TiO} 2$ incorporado. Outros fatores relevantes foram a textura superficial da peça e condições ambientais, tais como concentração de poluente, radiação UV, umidade relativa do ar e velocidade do fluxo.

\subsection{Experimentos complementares para projeto} Considerando o objetivo da pesquisa definida previamente, o grupo foi ao laboratório testar possibilidades de uso de resíduos na massa, de forma a diminuir os custos e proporcionar uma destinação aos resíduos. Os procedimentos adotados podem ser melhor verificados em Pinto e outros (2020) e apresenta-se aqui apenas alguns procedimentos e testes realizados para exemplificação.

Para verificar o efeito do cimento misturado com os resíduos referidos anteriormente, realizamos experiências usando o cimento Portland escuro e o claro (branco). A figura 8 mostra alguns resultados de testes com a aplicação de resíduos no cimento Portland escuro. Na primeira imagem foi usado resíduo de madeira, na segunda imagem resíduo de papel e na terceira, resíduo têxtil.
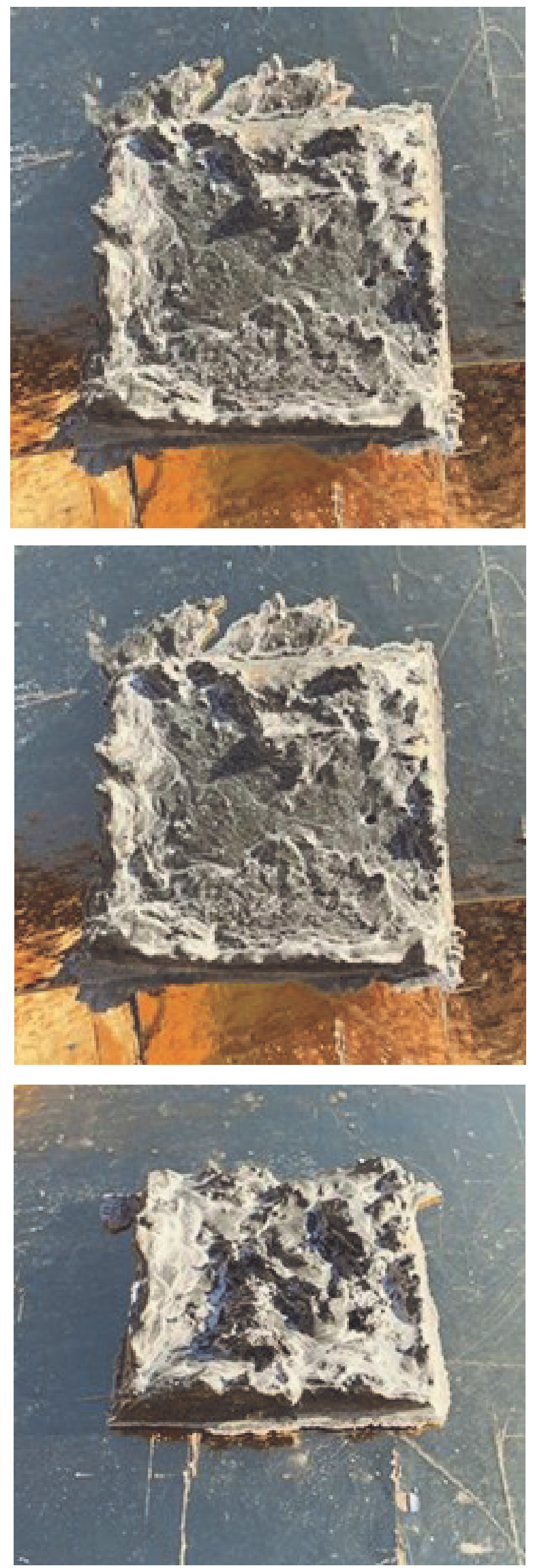

Figura 8 - Experimentos no cimento Portland escuro. Fonte: Pinto e outros (2020). 


\subsection{Projeto de mobiliário urbano}

A proposta de projeto aqui demonstrada é o resultado de várias propostas elaboradas ao longo da disciplina Design e Desenvolvimento Sustentável, do curso de Design de Produto - Cerâmica e Vidro da Escola Superior de Artes e Design das Caldas da Rainha, em Portugal. A prática projetual transcorreu durante o período de Setembro de 2019 a Janeiro de 2020.

Diversas propostas foram obtidas com a aplicação das metodologias tradicionais de desenvolvimento de produtos. Após a etapa de geração de alternativas, duas propostas foram selecionadas, sendo que a proposta mostrada na figura 9 apresentou melhores resultados para uso em concreto comum. Maiores detalhes sobre esse projeto podem ser encontrados em Pinto e outros (2020).

A primeira imagem da figura 9 mostra o projeto de uma parada de ônibus e a segunda imagem mostra variações do projeto original, objetivando adequar a proposta para diferentes níveis de exigências em termos de número de usuários e fluxo de ônibus. de mobiliário urbano que sirva mais do que uma função. Ou seja, o equipamento muda a sua função conforme este é apresentado no espaço evolvente.

O produto consiste numa lastra de betão fotocatalitíco reforçado com varão de aço nervurado, que adapta um perfil com uma forma em "J". As peças podem ser usadas em conjunto ou individualmente e apresentadas de formas diferentes, conforme mostra a figura 10 .
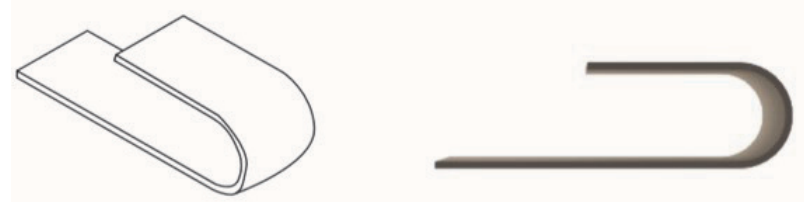

Figura 10 - Projeto proposto. Fonte: própria.

O produto escolhido é inteiramente projetado para construção em cimento fotocatalítico, que consiste numa mistura de argamassa de cal hidráulica aditivada com dióxido de titânio. Este agente (dióxido de titânio) reage, com a ajuda da radiação solar, com os óxidos poluentes do ar (exp. Óxido de azoto), transformando-os em nitratos. Este material é maioritariamente usado como estrutural em zonas de trafego automóvel elevado.

A figura 11 mostra a proposta projetual em uso, pousando a peça com a sua face mais comprida criando desse modo um assento. Colocando as peças na mesma posição repetidamente umas ao lado das outras tem-se a possibilidade de ajustar o comprimento do assento, permitindo desse modo um dimensionamento em função do número de usuários previstos.

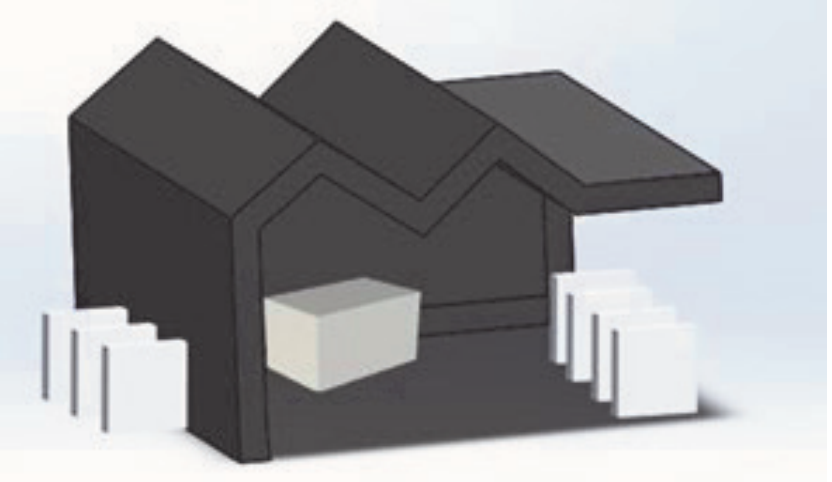

Figura 9 - Propostas projetuais com cimento. Fonte: Pintos e outros (2020)

Após a aplicação de metodologias projetuais foi escoIhido a opção denominada equipamento urbano "J". Este projeto tem como objetivo desenvolver um equipamento

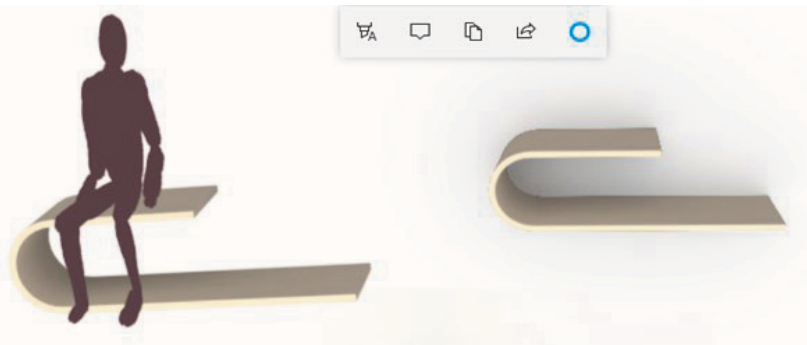

Figura 11 - Projeto proposto - possibilidades de uso. Fonte: própria.

A figura 12 mostra outra possibilidade de uso. Invertendo a posição de assento da peça, criou-se uma superfície de repouso para o utilizador. Esta, tal como o assento, pode ser regulada em seu comprimento de acordo com o número de peças que são repetidas. 


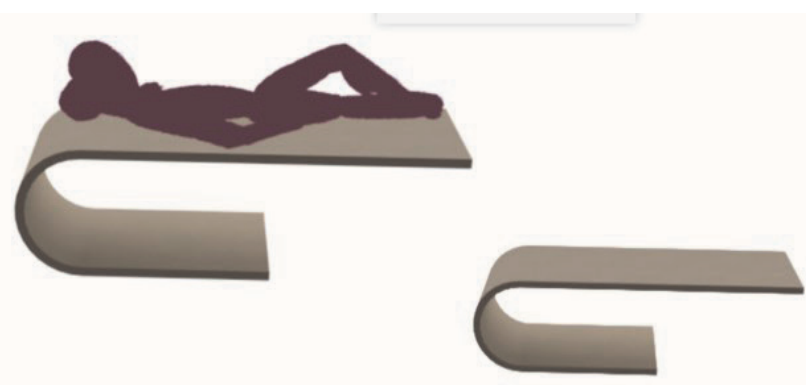

Figura 12 - Projeto proposto - outra possibilidade de uso. Fonte: própria.

Complementando o projeto, na figura 13, apresenta-se um conjunto de duas destas peças, com as quais pode-se criar uma canteiro. Isso é obtido colocando as duas peças na lateral e juntando a face de maior comprimento com a de menor.

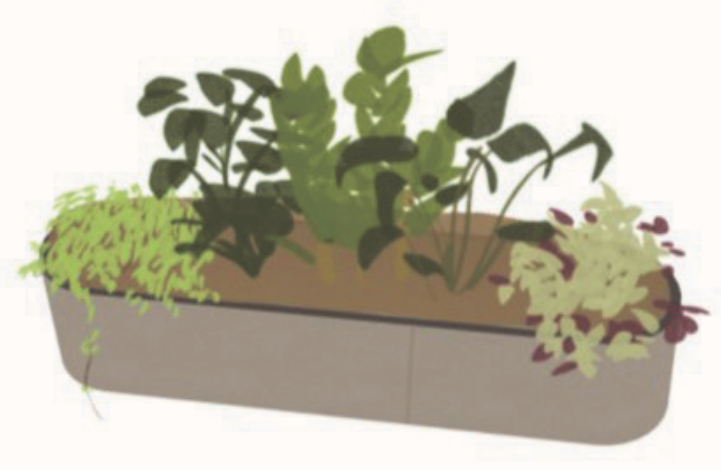

Figura 13 - Projeto proposto - possibilidade alternativa de uso. Fonte: própria.

As propostas foram submetidas a experimentos laboratoriais com construção de modelos computacionais e de escala reduzida. Posteriormente, com o desenvolvimento de protótipos, os testes serão melhor validados.

\section{CONSIDERAÇÕES FINAIS}

Este artigo teve por objetivo uma análise qualitativa para emprego do cimento fotocatalítico no mobiliário urbano. Isto está diretamente relacionado com o processo de escolha de materiais de um produto e com as dimensões da sustentabilidade (econômica, social e ambiental).

O mobiliário urbano foi utilizado como fator de análise em virtude de ser um produto presente em todo mundo, sendo de interesse geral nas áreas projetuais, com projetos realizados por arquitetos, engenheiros, designers, escultores, artistas, etc.

Por ser quantitativo e qualitativo por essência, o modelo ESA é ideal para ser utilizado no presente estudo, assim como toda e qualquer análise que envolva a sustentabilidade. Sua consideração abrange análise de critérios econômicos, de fabricação e ambientais que são facilmente mensurados mediante análise estatística, bem como considerações ergonômicas, de segurança e de mercado que não são tão fáceis de serem mensurados, exigindo uma boa interpretação qualitativa nas análises.

Também é possível considerar aspectos cujas análises envolvem emoção, sentimento, preconceitos e cultura, totalmente qualitativos e difíceis de mensuração.

Dentro desse cenário, este artigo teve como objetivo a análise e exploração de possíveis aplicações do cimento fotocatalítico em mobiliário urbano. Com a introdução deste material cria-se oportunidades de criar estruturas que purifiquem o ar do local onde estes são colocados.

A conclusão conceitual é que essa prática irá melhorar a qualidade de vida da população dos grandes centros urbanos, porque o cimento fotocatalítico tem características similares ao cimento comum como durabilidade, resistência e boa relação custo $\mathrm{x}$ benefício, acrescidas do bom desempenho do ponto de vista ambienta.

Entende-se desta forma que o uso consciente deste material poderá vir a melhorar o meio ambiente, proporcionando também ganhos industrias e desenvolvimento regional.

\section{REFERÊNCIAS}

ABNT - ASSOCIAÇÃO BRASILEIRA DE NORMAS cações, mobiliário, espaços e equipamentos urbanos. Rio de Janeiro, 2004.

CALLISTER JR, William D, RETHWISCH, David G. Ciência e Engenharia de Materiais - uma introdução. 9 ed. Rio de Janeiro, LTC, 2016.

GIL, Erica Alexandra Balata. O banco público - significado e importância deste equipamento no espaço público. Mestrado em Design de Equipamento - Universidade de Lisboa (dissertação de mestrado). 2011.

HESKETT, John. El diseño en la vida cotidiana. Barcelona: Gustavo Gili SA, 2005.

LIBRELOTTO, Lisiane Ilha. Modelo para Avaliação de Sustentabilidade na Construção Civil nas Dimensões Econômica, Social e Ambiental (ESA): Aplicação no setor de edificações. São Paulo: Blucher Acadêmico, 2009.

MANZINI, Ezio; VEZZOLI, Carlo. O desenvolvimento de produtos sustentáveis: requisitos ambientais dos produtos industriais. SÃO PAULO: EDUSP, 2002.

MELO, João Victor Staub de. Desenvolvimento de peças pré-moldadas de concreto fotocatalíticas para 
pavimentação e purificação do ar. Dissertação de mestrado. PPGEC - Programa de Pós-graduação em Engenharia Civil, UFSC, 2012.

MONTENEGRO, Glidson Megomeceno. A produção de mobiliário urbano em espaços públicos - o desenho de mobiliário urbano nos projetos de reordenamento das orlas do Rio Grande do Norte. PPGAU UFRN, Natal, 2005 (dissertação de mestrado)

PINTO, Ana Filipa Nunes; RODRIGUES, Liliane Abegão; FRADE, José Manuel Couceiro Barosa Correia; FERROLI, Paulo Cesar Machado. Cimento e resíduos industriais no mobiliário urbano. ENSUS 2020 - VIII Encontro de Sustentabilidade em Projeto. Anais, volume 4, p. 58-67. YÜCEL, Gökçen Firdevs. Street furniture and amenities: Designing the user-oriented urban landscape. Advances in Landscape Architecture. IntechOpen,2013 http://dx.doi.org/10.5772/55770.

\section{AUTORES}

ORCID:-

BERNARDO METZNER SERRA REYNAULD DA SILVA | Instituto Politécnico de Leiria | IPL - LIDA - ESAD-CR| Caldas da Rainha - Portugal | Correspondência para: Rua Isidoro Inácio Alves de Carvalho, Campus 3, 2500-321 Caldas da Rainha - Portugal | E-mail: bmsrsilva@gmail.com

ORCID: -

JOSÉ MANUEL COUCEIRO BAROSA CORREA FRADE, Dr. | Instituto Politécnico de Leiria | IPL - LIDA - ESAD-CR| Caldas da Rainha - Portugal | Correspondência para: Rua Isidoro Inácio Alves de Carvalho, Campus 3, 2500-321 Caldas da Rainha - Portugal | E-mail: jose.frade@ipleiria.pt

ORCID: https://orcid.org/0000-0002-6675-672X

PAULO CESAR MACHADO FERROLI, Dr. | Universidade Federal de Santa Catarina - UFSC | Virtuhab| Florianópolis, SC. Brasil | Correspondência para: Campus Universitário Reitor João David Ferreira Lima, s/no Trindade - Florianópolis - SC CEP: 88040-900 | E-mail: pcferroli@gmail.com

\section{COMO CITAR ESTE ARTIGO}

SILVA, Bernardo Metzner Serra Reynauld da; FRADE, José Manuel Couceiro Barosa Correa; FERROLI, Paulo Cesar Machado. Proposta de Uso do Cimento Fotocatalítico em Mobiliário Urbano - Estudo de Caso em Portugal. MIX Sustentável, [S.I.], v. 6, n. 1, p. 79-88, mai. 2020. ISSN 24473073. Disponível em:<http://www.nexos.ufsc.br/index.php/mixsustentavel>. Acesso em: dia mês. ano. doi:https://doi. org/10.29183/2447-3073.MIX2020.v6.n2.79-88.

DATA DE ENVIO: 08/05/2020

DATA DE ACEITE: $11 / 05 / 2020$ 